\title{
Enhancement of dissolution profile of poorly aqueous soluble atorvastatin calcium by binary and ternary solid dispersion techniques
}

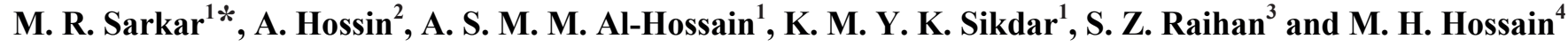 \\ ${ }^{1}$ Department of Pharmaceutical Technology, University of Dhaka, Bangladesh \\ ${ }^{2}$ Executive, Square Pharmaceutical Limited, Bangladesh \\ ${ }^{3}$ Department of Clinical Pharmacy and Pharmacology, University of Dhaka, Bangladesh \\ ${ }^{4}$ BCSIR Laboratories, BCSIR, Dhaka-1205
}

Received: 18 March 2021

Revised: 31 March 2021

Accepted: 31 March 2021

DOI: https://doi.org/10.3329/bjsir.v56i3.55964

\begin{abstract}
Atorvastatin calcium (ATV) is an HMG-CoA (3-hydroxy-3-methylglutaryl coenzyme A) reductase inhibitor commonly known as a cholesterol-lowering agent. As a poorly water-soluble drug its absolute bioavailability is very low. To increase the water solubility as well as oral bioavailability, different hydrophilic carriers were used in different ratios (1:0.5, 1:1 and 1:2) to prepare reproducible binary and ternary solid dispersion formulations of ATV by simple physical mixing $(\mathrm{PM})$ and fusion or melting technique. In vitro dissolution studies results revealed that in all cases, the cumulative percent drug release from ATV ternary SD formulations were greater than binary formulations, some marketed products and pure ATV powder. The order of the carriers in enhancing the drug release was found as kollidon $90 \mathrm{~F}>$ pregelatinized starch $>$ lutrol $>$ kollidon $12 \mathrm{~F}$ (99.1\%, 98.8\%, 96\% and 95\% respectively) for ternary SD formulations whereas pure ATV powder and marketed products showed cumulative percentage release $70.8 \%, 68.9 \%$ (B1) and $73.1 \%$ (B2), respectively. The best-out performed ternary SD formulation ATV:Kollidon $90 \mathrm{~F}(1: 2)$ were further characterized using FT-IR and SEM. SEM analyses indicated conversion of crystal drug to amorphous form and FT-IR data suggested that little or no interaction between the drug and polymer.
\end{abstract}

Keywords: Hydrophilic polymers; Physical mixing; Fusion method; Solid dispersion; Dissolution

\section{Introduction}

Improving the oral bioavailability of poorly aqueous soluble drugs remains the most difficult aspects in the current drug development process (Ali and Al-Khedairy, 2019; Sharma et al., 2009). It is estimated that nearly $40 \%$ of API with current market approval and about $90 \%$ of molecules/chemical entities in the discovery pipeline have been shown very low aqueous solubility (Kalepu and Vijaykumar, 2015; Lawrence, 1999). Drugs belong to class II of the Biopharmaceutics Classification System (BCS), tend to have a low dissolution (\%) rate and poor or low oral bioavailability (Frizon et al., 2013). These drugs are associated with slower absorption rate from the oral route which is a most natural, convenient and safe route for drug administration, therefore drug dissolution is considered the rate-limiting step (Charman, 2000). If solid oral dosages forms are not released completely in the gastrointestinal area, they might show poor bioavailability particularly for drugs which belong to BCS class II. To enhance the solubility of poorly water-soluble drugs, numerous formulation strategies have been investigated and developed (Kalepu and Vijaykumar, 2015; Pabari et al., 2014; Sharma et al., 2009). Several approaches and techniques like physical, chemical and other modifications or techniques such as crystal engineering, particle size reduction, use of surfactant, salt formation, hydrotropic, prodrugs, $\mathrm{pH}$ adjustments, micro-emulsion, complexation, co-solvency, micelles and nano crystallization have frequently been implemented to increase the dissolution rate and water solubility of poorly soluble drugs (Chaudhary et. al., 2012; 
Friedrich et al., 2006; Frizon et al., 2013; Lai et al., 2011; Merisko-Liversidge and Liversidge, 2008; Shamsuddin et al., 2016; Sharma et al., 2009). To increase the water solubility of low aqueous soluble drug, solid dispersion is considered one of the most common and effective methods (Shamsuddin et al., 2016). In solid dispersion technique, the solubility of the poorly water-soluble drug is increased using different hydrophilic carriers in which the drug is molecularly dispersed (Chiou and Riegelman, 1971). Crystalline drugs are transformed into amorphous forms by different hydrophilic polymers in solid dispersion approach (Choi and Park, 2017).

Atorvastatin is an inhibitor of HMG-CoA reductase which catalyzes the transformation of hydroxymethyl glutarate to mevalonate and this molecule is extensively used for lowering total cholesterol (TC), apolipoprotein B (Apo B), triglycerides (TG) as well as low-density lipoprotein cholesterol (LDL-C) (Ali and Al-Khedairy, 2019; Bobe et al., 2011; Narasaiah et al., 2010; Sarkar et al., 2014). It is a statin medication belongs to BCS class II drugs whose absolute bioavailability has reported less than $12 \%$ due to its' very low phosphate buffers $(\mathrm{pH} 7.4)$ and water solubility (Ahjel and Dumitru, 2009; Mukhtar et al., 2005). As mentioned previously due to its low oral bioavailability, improvement of water solubility of this drug is a valuable approach to improve therapeutic efficacy and solid dosage form design. Different techniques have been implemented to increase the aqueous solubility of atorvastatin such as nano-suspension, co-crystals, Microwave induced solubility enhancement, spray-drying and supercritical antisolvent (SAS) process, self-emulsifying drug delivery systems, cyclodextrin complexation and solid dispersion approaches (Arunkumar et al., 2009; Kim et al., 2008; Maurya et al., 2010; Naqvi et al., 2020; Palem et al., 2009; Rodde et al., 2014). The solubility and dissolution rate of atorvastatin have been improved by solid dispersion approach through different hydrophilic polymers such as PEG 6000, polyvinylpyrrolidone-K30, Soluplus ${ }^{\circledR}$, PVP VA64, HPMC, Poloxamer 188 (Bobe et al., 2011; Dong et al., 2018; Ha et al., 2014; Hu et al., 2014; Jahan et al., 2013; Shamsuddin et al., 2016). The dissolution profile of atorvastatin was studied and reported to our previous publications (Sarkar et al., 2012; Sarkar et al., 2014) using physical mixing and fusion techniques. Improved dissolution rates of atorvastatin from SD formulations compared to the pure active has been reported (Sarkar et al., 2012; Sarkar et al., 2014). Previously pregelatinized starch, poloxamer 407, hydroxypropyl methylcellulose and sodium carboxymethyl cellulose were used to prepare binary solid dispersion (SD) of atorvastatin calcium and increased the cumulative per cent release from $74 \%$ to $96 \%$ after 60 minutes (Sarkar et al., 2012). In another study, both physical mixture and melt solvent techniques were implemented to formulate the solid dispersion of atorvastatin with PVK30 and Kollicoat IR and successfully enhanced the solubility of this API (Sarkar et al., 2014).

In this study, reproducible binary and ternary solid dispersion formulations of atorvastatin using simple physical mixing and fusion technique has been prepared and investigated for dissolution rate. The primary objective of the current study was to improve the aqueous solubility, dissolution profile and release rate of the atorvastatin calcium using solid dispersion approach.The polymers kollidon 90F, kollidon 12F, lutrol, and pregelatinized starch were used to prepare binary and ternary SD formulations are very cheap and widely used in different solid dosage forms. After extensive literature search, it was found that these hodrophilic polymers were not previously investigated with this API to formulate solid dispersion formulations.

\section{Material and methods}

Atorvastatin calcium was collected from Beximco Pharmaceuticals Ltd., Bangladesh. Pregelatinized starch, lutrol, kollidon 90F, PEG 6000 and kollidon 12F were purchased from BASF, Germany. Electronic balance of Metlar Toledo, Japan, USP dissolution apparatus II of Electrolab, Scanning Electron Microscopy (SEM), JEOL, Japan, double beam UV-spectrophotometer of Shimadzu, Japan and Fourier Transform Infrared Spectroscopy (FTIR) machine of Perkin Elmer, USA were used to conduct the study. All these instruments are available in Department of Pharmaceutical Technology Laboratory and CARS, university of Dhaka, Bangladesh.

Preparation of atorvastatin-hydrophilic polymer binary and ternary solid dispersion formulations

Physical mixtures of atorvastatin calcium with the hydrophilic polymers were formulated by simply mixing them for 15 minutes using a mortar-pestle (Table I). $100 \mathrm{mg}$ Polyethylene glycol 6000 (PEG 6000 ) was taken in an aluminum pan on a hot plate and allowed to melt at a temperature $60-65^{\circ} \mathrm{C}$ (Sarkar et al., 2012). Different ratios of atorvastatin calcium (ATV) and hydrophilic polymers were added in the PEG (molten). The 
Table I. Formulations were prepared by physical mixing (PM) and fusion/melting method

\begin{tabular}{lccccccc}
\hline $\begin{array}{l}\text { Formulations } \\
\text { code }\end{array}$ & PML & PMK90 & PMK12 & SDPS & SDL & SDK90 & SDK12 \\
\hline $\begin{array}{l}\text { Atorvastatin } \\
(\mathrm{mg})\end{array}$ & 10 & 10 & 10 & 10 & 10 & 10 & 10 \\
$\begin{array}{l}\text { Lutrol (mg) } \\
\text { Kollidon 90F } \\
(\mathrm{mg})\end{array}$ & $5 / 10 / 20$ & - & - & - & 20 & - & - \\
$\begin{array}{l}\text { Kollidon 12F } \\
(\mathrm{mg})\end{array}$ & - & $5 / 10 / 20$ & - & - & - & 20 & - \\
$\begin{array}{l}\text { Pregelatinized } \\
\text { starch (mg) }\end{array}$ & - & - & $5 / 10 / 20$ & - & - & - & 20 \\
PEG 6000 & - & - & - & 20 & - & - & - \\
\hline
\end{tabular}

PML: Physical Mixing Lutrol; PMK90: Physical Mixing Kollidon 90F; PMK12: Physical Mixing Kollidon 12F; SDPS: Solid dispersion Pregelatinized starch; SDL: Solid dispersion Lutrol; SDK90: Solid dispersion Kollidon 90F; SDK12: Solid dispersion Kollidon 12F; 5/10/20 mg: 1:0.5, 1:1 and 1:2 ratios of atorvastatin and polymers.

mixture was continuously stirring with a glass rod to assure homogenous mixing. The mixtures were then cool down to room temperature $\left(30^{\circ} \mathrm{C}\right)$ to get the dry and solid mass of the drug and polymer mixtures. Mortar-pestle was used to pulverize the mixtures. Prepared formulations were then filled in airtight small vials $(5 \mathrm{ml})$ and the vials were kept and preserved in a desiccator until further use (Sarkar et al., 2014).

\section{In vitro dissolution study}

In vitro dissolution assays of atorvastatin calcium (ATV), binary (PM) and ternary solid dispersion (SD) formulation was done in USP type II paddle-type apparatus (mentioned previously) using distilled water $(900 \mathrm{ml})$ maintaining the temperature at $37{ }^{\circ} \mathrm{C}$ and paddle rotation at $50 \mathrm{rpm}$ (Iqbal et al., 2020; Sarkar et al., 2012; Sarkar et al., 2014). Each time, $5 \mathrm{ml}$ of dissolution medium (distilled water) was withdrawn from the dissolution apparatus at predetermined 5, 10, 20, 30, 40, 50 and $60 \mathrm{~min}$ time intervals and $5 \mathrm{ml}$ fresh distilled water was added to maintain the sink $(900 \mathrm{ml})$ condition (Sarkar et al., 2012; Sarkar et al., 2014). The collected samples (5 ml each) were filtered through filter paper/cotton and analyzed for atorvastatin content in UV-VIS spectrophotometer. The lambda max was used to collect the absorption data at $248 \mathrm{~nm}$. The calibration curve, FT-IR and SEM analyses were performed using standard methods described previously (Bobe et al., 2011; Sarkar et al., 2014).

\section{Drug release kinetics analysis}

Different kinetics models like Higuchi, Hixson-Crowell, zero order and first order models were performed to determine the drug release kinetics of the ternary solid dispersion formulations (Kayes et al., 2019). Moreover, one way analysis of variance (ANOVA) was performed among the optimized physical mixing (PM) and solid dispersions (SD) formulations for determining how the drug released significantly from these formulations.

\section{Results and discussion}

The dissolution profile of atorvastatin calcium was investigated in distilled water medium for 60 minutes. Cumulative release percentage was gradually increased from $48 \%$ (10 $\mathrm{min}$ ) to $70.8 \%$ (60 min) (Fig. 1) (Sarkar et al., 2014). So, different polymers having dissolution enhancing

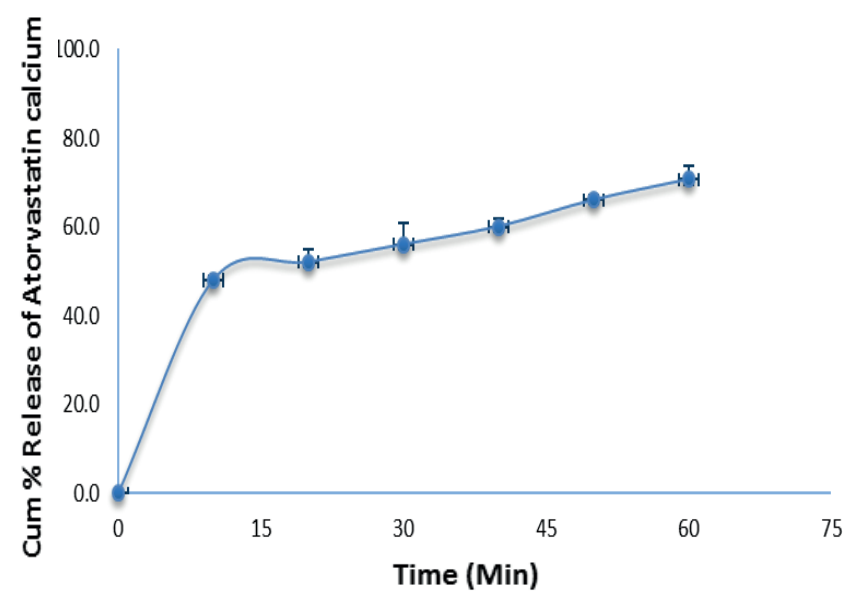

Fig. 1. Cumulative percentage $(\%)$ release of pure atorvastatin calcium powder in distilled water 


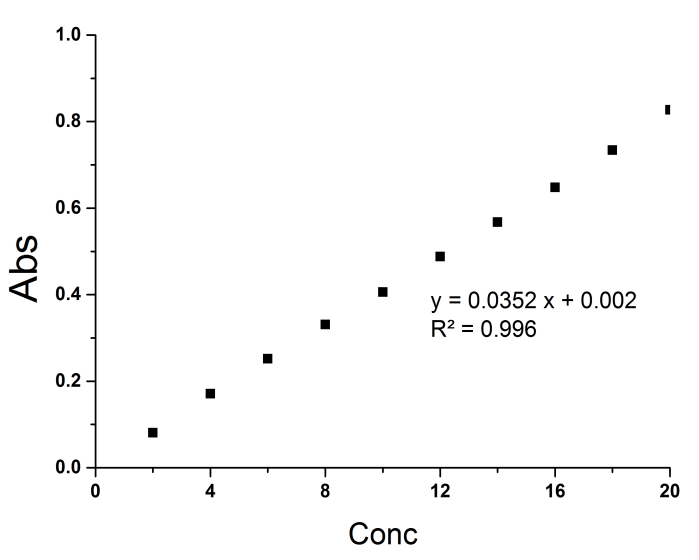

Fig. 2. Calibration curve atorvastatin calcium in distilled water

properties such as kollidon 90F, kollidon 12F, lutrol, pregelatinized starch were used to prepare solid dispersion formulations with atorvastatin with an aim to increase dissolution profile of atorvastatin.
Drug release study of atorvastatin calcium from binary solid dispersion formulations

Atorvastatin-Kollidon 90F binary SDs was prepared by physical mixing (PM) technique where atorvastatin-kollidon 90F ratio was maintained at 1.0:0.5 (PMK90 A), 1.0:1.0 (PMK90 B) and 1.0:2.0 (PMK90 C). Release of atorvastatin was checked for 60 minutes and it was observed that high amount of Kollidon 90F improved the release rate of atorvastatin from $71 \%$ to $89 \%$. For pure drug powder, the cumulative release was $71 \%$ after 60 minutes of dissolution, whereas release value was approximately $82.0 \%$ from PMK90 A. As the content of kollidon 90F was increased, release data were also found to be increased accordingly. For $1: 1$, approximately $84.0 \%$ and for $1: 2$ it was $88.0 \%$ (Figure 3). Hydrophilic polymer kollidon $90 \mathrm{~F}$ improves the bioavailability of some hardly soluble drugs (Herbrink et al., 2018). Kollidon $90 \mathrm{~F}$ forms a water-soluble complex with some drug. It also accelerates the dissolution rate of the poorly aqueous soluble drug from solid dosage forms such as lovastatin (Sarkar et al., 2021). Tantishaiyakul et al (1999) also reported about this dissolution enhancement property of kollidon 90F where they used kollidon 90F to increase the dissolution of piroxicam. Kollidon $90 \mathrm{~F}$ is an excellent

Table II. Different kinetic parameters of atorvastatin (ATV) release for binary physical mixing (PM) formulations (Sarkar et al., 2012)

\begin{tabular}{|c|c|c|c|c|c|c|c|c|c|}
\hline \multirow[t]{2}{*}{ PM } & \multirow[t]{2}{*}{$\begin{array}{c}\text { Ratio } \\
\text { Drug:Polymer }\end{array}$} & \multicolumn{2}{|c|}{ Zero Order } & \multicolumn{2}{|c|}{ First Order } & \multicolumn{2}{|c|}{ Higuchi Model } & \multicolumn{2}{|c|}{$\begin{array}{c}\text { Hixson-Crowell } \\
\text { Model }\end{array}$} \\
\hline & & $\mathrm{R}^{2}$ & $\mathrm{~K}_{0}$ & $\mathrm{R}^{2}$ & $\mathrm{~K}_{1}$ & $\mathrm{R}^{2}$ & $\mathrm{~K}_{\mathrm{h}}$ & $\mathrm{R}^{2}$ & $\mathrm{~K}_{\mathrm{HC}}$ \\
\hline & $1: 0.5$ & 0.74 & 63.345 & 0.91 & -0.5816 & 0.94 & 0.0125 & 0.86 & 1.584 \\
\hline \multirow{3}{*}{$\begin{array}{l}\text { PMK12 } \\
\text { (Kollidon } \\
\text { 12F) }\end{array}$} & $1: 1$ & 0.72 & 65.059 & 0.91 & -0.6397 & 0.93 & 0.0119 & 0.85 & 1.695 \\
\hline & $1: 2$ & 0.75 & 68.927 & 0.94 & -0.7261 & 0.94 & 0.0116 & 0.89 & 1.8722 \\
\hline & $1: 0.5$ & 0.67 & 60.572 & 0.84 & -0.5763 & 0.88 & 0.0121 & 0.79 & -1.5435 \\
\hline \multirow{3}{*}{$\begin{array}{l}\text { PMK90 } \\
\text { (Kollidon } \\
90 \mathrm{~F})\end{array}$} & $1: 1$ & 0.64 & 65.137 & 0.85 & -0.6872 & 0.88 & 0.011 & 0.78 & -1.7692 \\
\hline & $1: 2$ & 0.60 & 66.761 & 0.83 & -0.7863 & 0.86 & 0.0102 & 0.75 & -1.9316 \\
\hline & $1: 0.5$ & 0.72 & 62.893 & 0.89 & -0.582 & 0.93 & 0.0124 & 0.84 & -1.5793 \\
\hline \multirow{2}{*}{$\begin{array}{l}\text { PML } \\
\text { (Lutrol) }\end{array}$} & $1: 1$ & 0.74 & 65.498 & 0.91 & -0.6476 & 0.93 & 0.012 & 0.86 & -1.7124 \\
\hline & $1: 2$ & 0.73 & 73.749 & 0.96 & -0.9081 & 0.94 & 0.0107 & 0.90 & -2.197 \\
\hline Pure ATV & - & 0.71 & 55.183 & 0.85 & -0.4424 & 0.92 & 0.0139 & 0.81 & -1.2683 \\
\hline
\end{tabular}




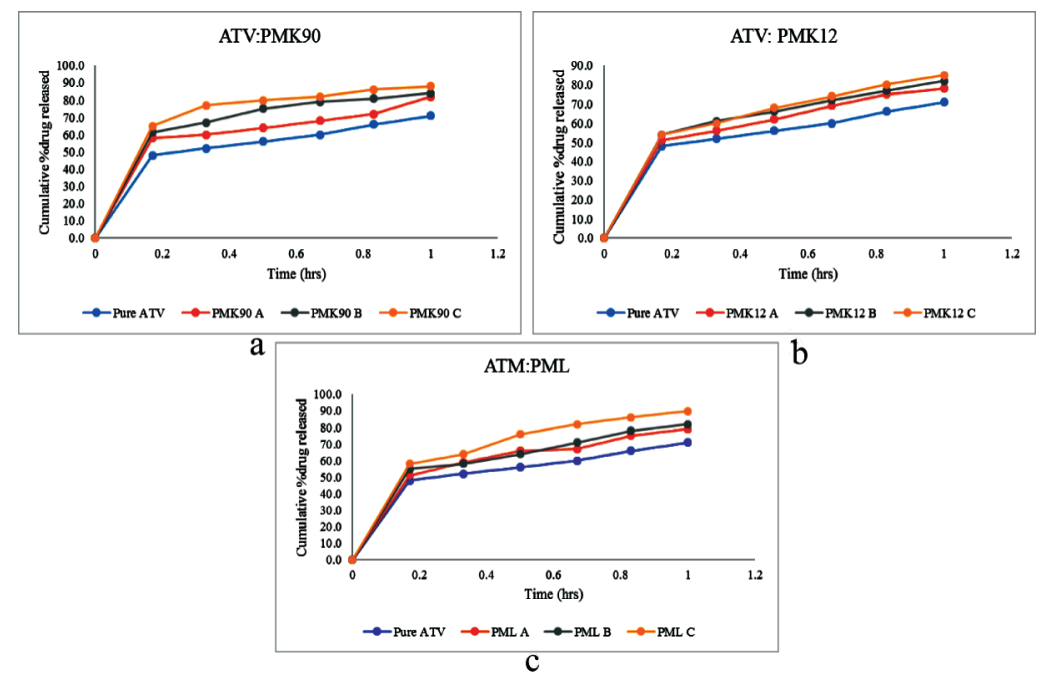

Fig. 3. Cumulative \% release (Zero order) of atorvastatin from atorvastatin-kollidon 90F (a), kollidon $12 \mathrm{~F}$ (b) and lutrol (c) binary SD prepared by physical mixing technique

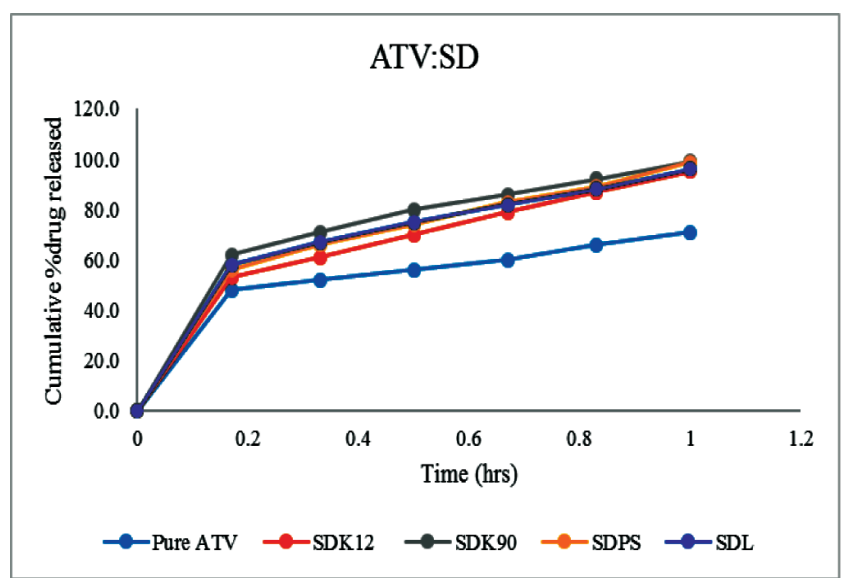

Fig. 4. Cumulative percentage release (zero order) of atorvastatin from ternary SD formulation prepared by fusion technique

polymer for increasing solubility, dissolution profile of the poorly soluble drug.

Atorvastatin-kollidon $12 \mathrm{~F}$ binary SDs formulations were prepared by simple physical mixing technique. Release value was found approximately $78 \%$ at 1:0.5 ratio. As the concentration of kollidon $12 \mathrm{~F}$ was increased, release data were also found to be increased accordingly. For 1:1 (PMK12 B), the cumulative release was approximately $82 \%$ and for $1: 2$, it was $86 \%$ respectively (Figure 3 ). The dissolution enhancement of BCS class II drugs has been reported previously when kollidon $12 \mathrm{~F}$ was used as a carrier (Chowdary and Rao, 2000; Herbrink et al., 2018).

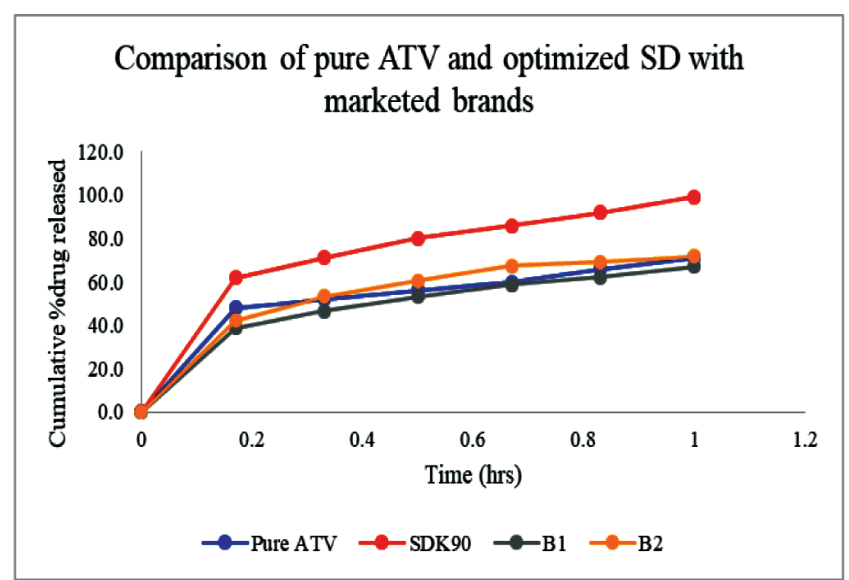

Fig. 5. Comparison of pure ATV and optimized SD with marketed brands

Chowdary and Rao (2000) reported the enhanced dissolution profile of itraconazole using kollidon $12 \mathrm{~F}$.

Binary SD formulation of atorvastatin-lutrol was prepared and screened for atorvastatin release rate. Release value was approximately $80 \%$ for $1: 0.5$ ratio and $91.2 \%$ for $1: 2$ (Figure 3) ratio, which was significantly higher than the $1: 0.5$ and $1: 1$ ratios (Table II, $\mathrm{p}<0.05$ ). Previously, the dissolution profile of repaglinide and olanzapine was increased by lutrol, (Cavallari et al., 2013; Patel et al., 2011).

The investigation of the release curve of the drug for PMs was done to check the goodness of fit of the various model 
Table III. ANOVA (Analysis of Variance) of the optimized PMs of atorvastatin (Sarkar et al., 2012)

\begin{tabular}{|c|c|c|c|c|c|c|c|c|}
\hline \multirow[t]{2}{*}{ PM } & $\begin{array}{l}\text { Ratio } \\
\text { ATV:Polymer }\end{array}$ & $\begin{array}{l}\text { Source of } \\
\text { Variation }\end{array}$ & SS & $\mathrm{df}$ & MS & $F$ & P-value & $\mathrm{F}_{\text {crit }}$ \\
\hline & $1: 0.5$ & $\begin{array}{l}\text { Between } \\
\text { Groups }\end{array}$ & 2730.08 & 1 & 2730.08 & 11.76 & 0.01 & 4.965 \\
\hline \multirow{5}{*}{$\begin{array}{l}\text { PMK12 } \\
\text { (Kollidon } \\
\text { 12F) }\end{array}$} & & $\begin{array}{l}\text { Within } \\
\text { Groups }\end{array}$ & 2320.83 & 10 & 232.08 & & & \\
\hline & $1: 1$ & $\begin{array}{l}\text { Between } \\
\text { Groups }\end{array}$ & 3400.33 & 1 & 3400.33 & 14.85 & 0.003 & 4.965 \\
\hline & & $\begin{array}{l}\text { Within } \\
\text { Groups }\end{array}$ & 2289.33 & 10 & 228.93 & & & \\
\hline & $1: 2$ & $\begin{array}{c}\text { Between } \\
\text { Groups }\end{array}$ & 3710.08 & 1 & 3710.08 & 15.14 & 0.003 & 4.965 \\
\hline & & $\begin{array}{l}\text { Within } \\
\text { Groups }\end{array}$ & 2450.83 & 10 & 245.08 & & & \\
\hline \multirow{6}{*}{$\begin{array}{l}\text { PMK90 } \\
\text { (Kollidon } \\
\text { 90F) }\end{array}$} & $1: 0.5$ & $\begin{array}{l}\text { Between } \\
\text { Groups }\end{array}$ & 3136.33 & 1 & 3136.33 & 14.66 & 0.003 & 4.965 \\
\hline & & $\begin{array}{l}\text { Within } \\
\text { Groups }\end{array}$ & 2139.33 & 10 & 213.93 & & & \\
\hline & $1: 1$ & $\begin{array}{l}\text { Between } \\
\text { Groups }\end{array}$ & 4695.13 & 1 & 4695.13 & 22.024 & 0.001 & 4.965 \\
\hline & & $\begin{array}{l}\text { Within } \\
\text { Groups }\end{array}$ & 2131.79 & 10 & 213.18 & & & \\
\hline & $1: 2$ & $\begin{array}{l}\text { Between } \\
\text { Groups }\end{array}$ & 5980.87 & 1 & 5980.87 & 28.654 & 0.0003 & 4.965 \\
\hline & & $\begin{array}{l}\text { Within } \\
\text { Groups }\end{array}$ & 2087.28 & 10 & 208.73 & & & \\
\hline \multirow{6}{*}{$\begin{array}{l}\text { PML } \\
\text { (Lutrol) }\end{array}$} & $1: 0.5$ & $\begin{array}{l}\text { Between } \\
\text { Groups }\end{array}$ & 2914.08 & 1 & 2914.083 & 12.810 & 0.005 & 4.965 \\
\hline & & $\begin{array}{l}\text { Within } \\
\text { Groups }\end{array}$ & 2274.83 & 10 & 227.483 & & & \\
\hline & $1: 1$ & $\begin{array}{l}\text { Between } \\
\text { Groups }\end{array}$ & 3267.00 & 1 & 3267.00 & 13.962 & 0.004 & 4.965 \\
\hline & & $\begin{array}{l}\text { Within } \\
\text { Groups }\end{array}$ & 2340.00 & 10 & 234.00 & & & \\
\hline & $1: 2$ & $\begin{array}{l}\text { Between } \\
\text { Groups }\end{array}$ & 5034.80 & 1 & 5034.80 & 19.788 & 0.001 & 4.965 \\
\hline & & $\begin{array}{l}\text { Within } \\
\text { Groups }\end{array}$ & 2544.43 & 10 & 254.44 & & & \\
\hline
\end{tabular}


Table IV. Kinetic parameters of atorvastatin (ATV) release from ternary solid dispersion (1:2 ratios) formulations (Sarkar et al., 2012)

\begin{tabular}{lcccccccc}
\hline SD & \multicolumn{2}{c}{ Zero Order } & \multicolumn{2}{c}{ First Order } & \multicolumn{2}{c}{ Higuchi Model } & \multicolumn{2}{c}{$\begin{array}{c}\text { Hixson-Crowell } \\
\text { Model }\end{array}$} \\
\cline { 2 - 9 } & $\mathrm{R}^{2}$ & $\mathrm{~K}_{0}$ & $\mathrm{R}^{2}$ & $\mathrm{~K}_{1}$ & $\mathrm{R}^{2}$ & $\mathrm{~K}_{\mathrm{h}}$ & $\mathrm{R}^{2}$ & $\mathrm{~K}_{\mathrm{HC}}$ \\
\hline SDK12 & 0.82 & 79.654 & 0.95 & -1.1351 & 0.98 & 0.0107 & 0.96 & -2.5635 \\
SDK90 & 0.75 & 79.938 & 0.87 & -1.6761 & 0.94 & 0.01 & 0.94 & -3.0945 \\
SDPS & 0.80 & 81.46 & 0.85 & -1.5604 & 0.97 & 0.0103 & 0.94 & -3.0095 \\
SDL & 0.77 & 77.94 & 0.94 & -1.1904 & 0.96 & 0.0105 & 0.94 & -2.6024 \\
Pure & 0.71 & 55.183 & 0.85 & -0.4424 & 0.92 & 0.0139 & 0.81 & -1.2683 \\
ATV & & & & & & & & \\
\hline
\end{tabular}

Table V. ANOVA analysis of the optimized SDs of atorvastatin

\begin{tabular}{|c|c|c|c|c|c|c|c|}
\hline Formulations & $\begin{array}{c}\text { Source } \\
\text { of } \\
\text { Variation }\end{array}$ & $\mathrm{SS}$ & df & $\mathrm{MS}$ & $\mathrm{F}$ & P-value & $\mathrm{F}_{\text {crit }}$ \\
\hline \multirow{2}{*}{ SDK90 } & $\begin{array}{l}\text { Between } \\
\text { Groups }\end{array}$ & 6538.00 & 1.00 & 6538.00 & \multirow{2}{*}{24.37} & \multirow[b]{2}{*}{0.001} & \multirow[b]{2}{*}{4.965} \\
\hline & $\begin{array}{l}\text { Within } \\
\text { Groups }\end{array}$ & 2682.81 & 10.00 & 268.28 & & & \\
\hline \multirow{2}{*}{ SDK12 } & $\begin{array}{l}\text { Between } \\
\text { Groups }\end{array}$ & 4602.083 & 1 & 4602.08 & \multirow{2}{*}{15.29} & \multirow{2}{*}{0.003} & \multirow{2}{*}{4.965} \\
\hline & $\begin{array}{l}\text { Within } \\
\text { Groups }\end{array}$ & 3010.833 & 10 & 301.08 & & & \\
\hline \multirow{2}{*}{ SDPS } & $\begin{array}{l}\text { Between } \\
\text { Groups }\end{array}$ & 5495.520 & 1.000 & 5495.520 & \multirow{2}{*}{18.488} & \multirow{2}{*}{0.002} & \multirow{2}{*}{4.965} \\
\hline & $\begin{array}{l}\text { Within } \\
\text { Groups }\end{array}$ & 2972.400 & 10.000 & 297.240 & & & \\
\hline \multirow{2}{*}{ SDL } & $\begin{array}{c}\text { Between } \\
\text { Groups }\end{array}$ & 5461.333 & 1.000 & 5461.333 & \multirow{2}{*}{20.083} & \multirow{2}{*}{0.001} & \multirow{2}{*}{4.965} \\
\hline & $\begin{array}{l}\text { Within } \\
\text { Groups }\end{array}$ & 2719.333 & 10.000 & 271.933 & & & \\
\hline
\end{tabular}

(Table II). The results confirm that the release curve was a poor fit to zero-order kinetics. However, the dissolution data were best fitted to the Higuchi model. The order of goodness to fit of different models for PMs was found: Higuchi model $>$ First order $>$ Hixson Crowell $>$ Zero order.
Drug release study of atorvastatin from ternary solid dispersion (SD) formulations prepared by fusion method

Atorvastatin ternary solid dispersion (SD) formulations were prepared by fusion/hot melting technique. In PM formulations, improved dissolution has been found for 1:2 


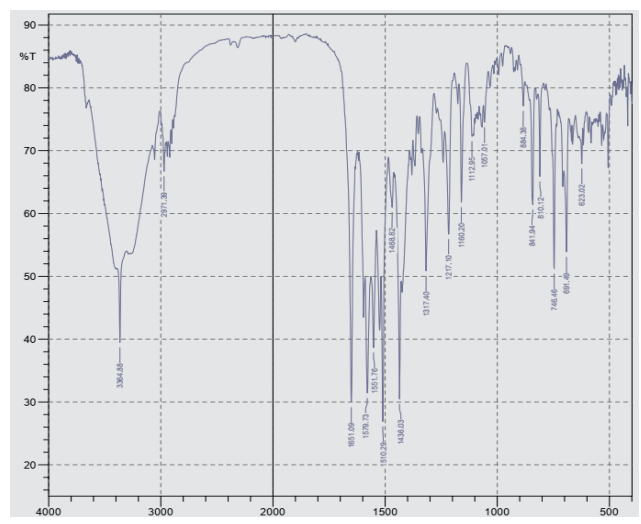

a

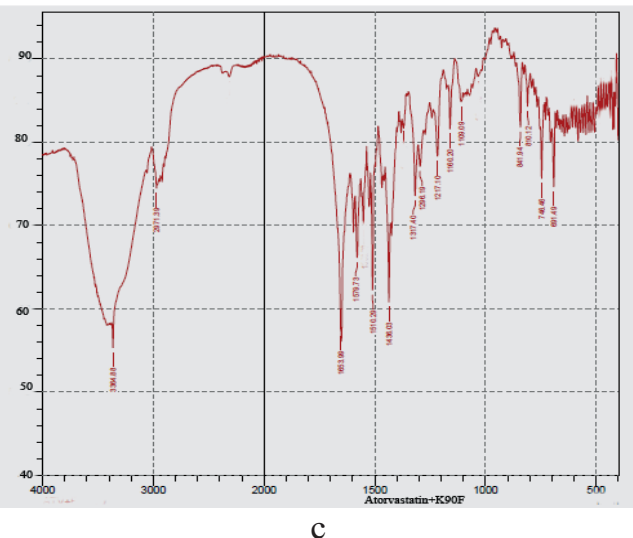

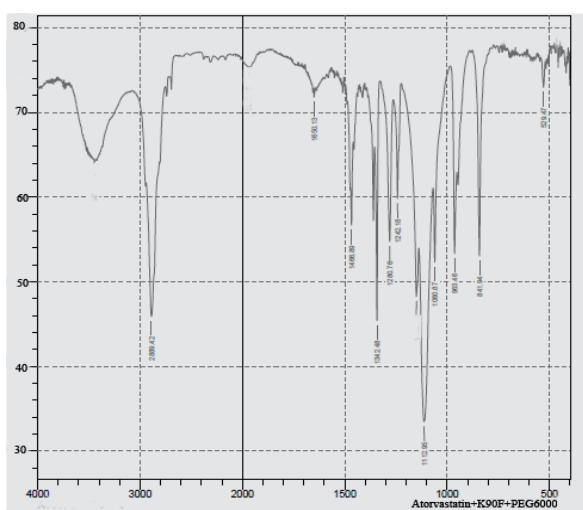

b

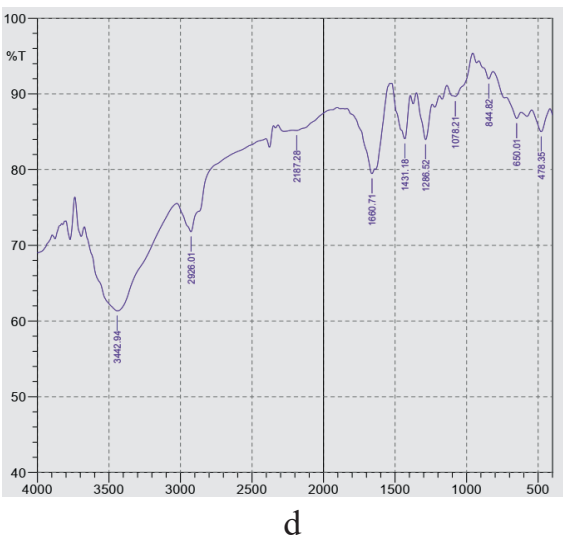

Fig. 6. FT-IR spectroscopy of (a) pure atorvastatin powder, (b) ternary solid dispersion formulation of atorvastatin and kollidon 90F (1:2), (c) binary atorvastatin and kollidon 90F (1:2) formulation and (d) pure Kollidon 90F
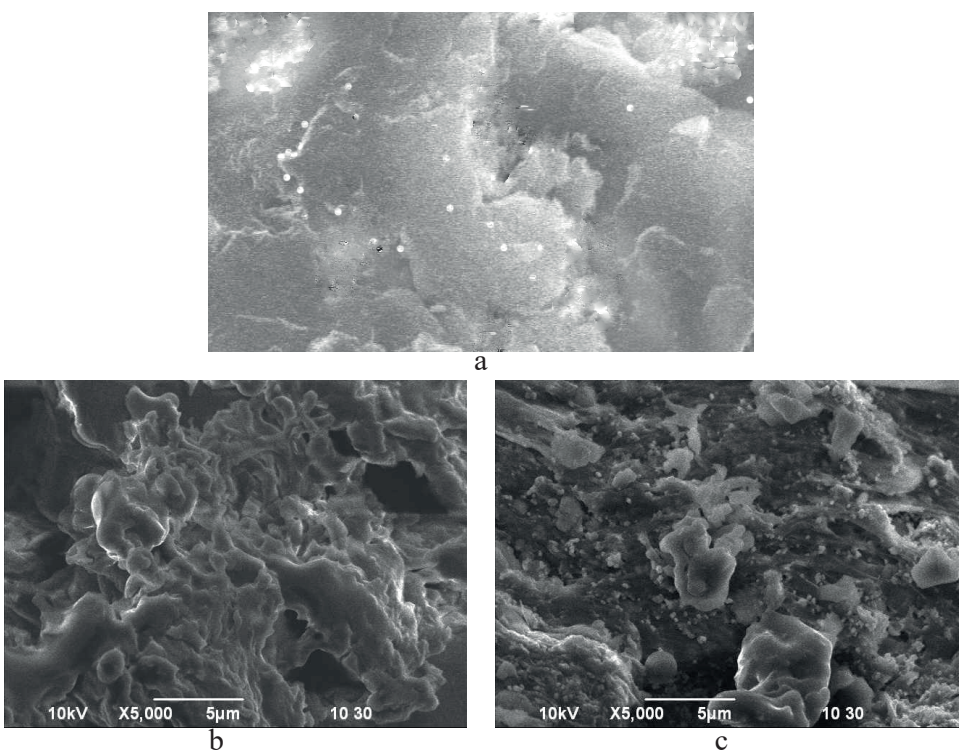

Fig. 7. Scanning electron microscopic (SEM) analyses of a. pure atorvastatin, b. ternary solid dispersion formulation atorvastatin and kollidon $90 \mathrm{~F}(1: 2)$ and c. binary formulation atorvastatin and kollidon 90F (1:2) 


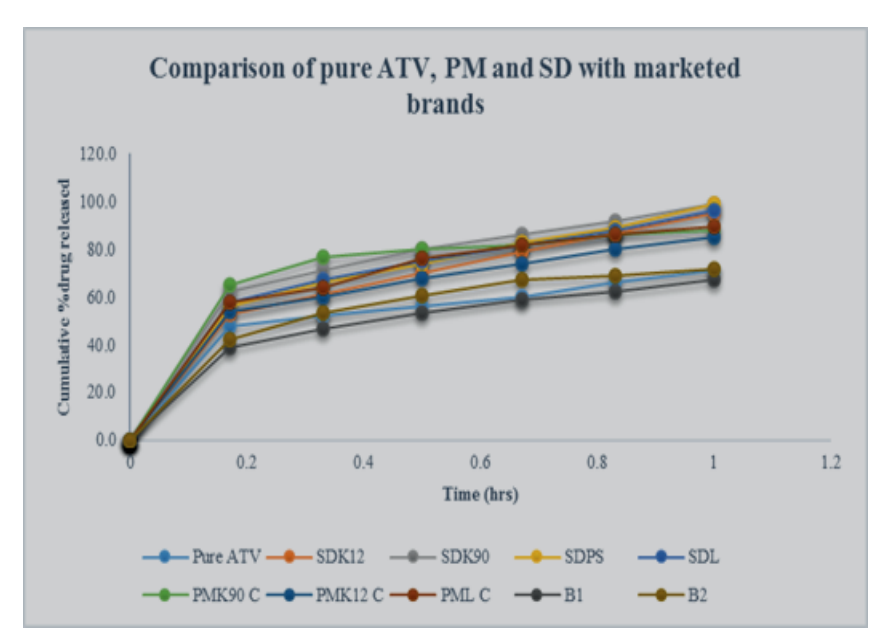

Fig. 8. Comparison of pure ATV, PM and SD with marketed brands B1 and B2

ratio for all the investigated excipients. Therefore, for ternary $\mathrm{SD}$ the ratio was fixed at 1:2. Release study was carried out following in vitro dissolution method where dissolution media was water and study was performed for 60 minutes as for PM techniques. A physical mixture of atorvastatin and pregelatinized starch reported to our previous study showed
$96 \%$ (1:2 ratios) cumulative percentage release of atorvastatin after 60 min (Sarkar et al., 2012). Atorvastatin-pregelatinized starch ternary SD was prepared by fusion technique. Release of atorvastatin from atorvastatin-pregelatinized starch ternary SD formulation was checked for 60 minutes (Figure 4). The release was found to be increased than the physical mixture. For pure drug, the release was $71 \%$ after 60 minutes, whereas release value was approximately $98.8 \%$ from ternary solid dispersion formulation. Ternary formulation of atorvastatin-lutrol (1:2) was prepared and the cumulative percentage release was found to be increased compared to binary formulations (91\% vs 96\%). Atorvastatin-kollidon 90F ternary SD formulation (1.0:2.0) showed nearly 99.1\% cumulative percentage release. On the other hand, kollidon $12 \mathrm{~F}$ increased the dissolution release rate to $95 \%$. Both these were higher than their physical mixture formulations. That indicates the fusion method is more effective than the physical mixture.

As for PM, the best fitted model of the dissolution data of ATV for ternary SD was Higuchi model (Table V and Figure 9). The order of the fitted model for the ternary SDs of ATV

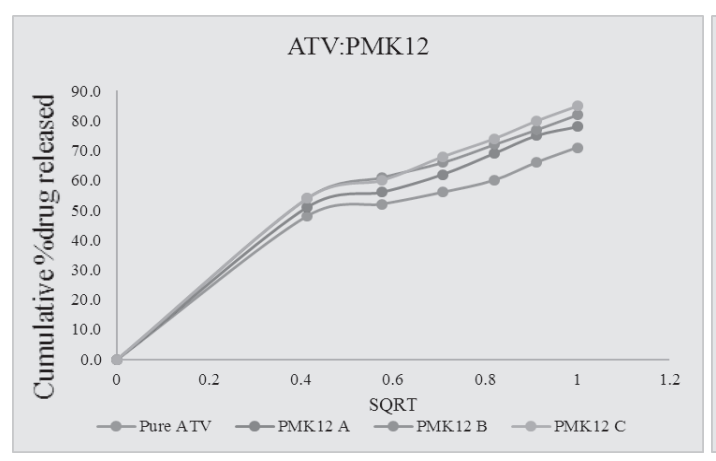

a

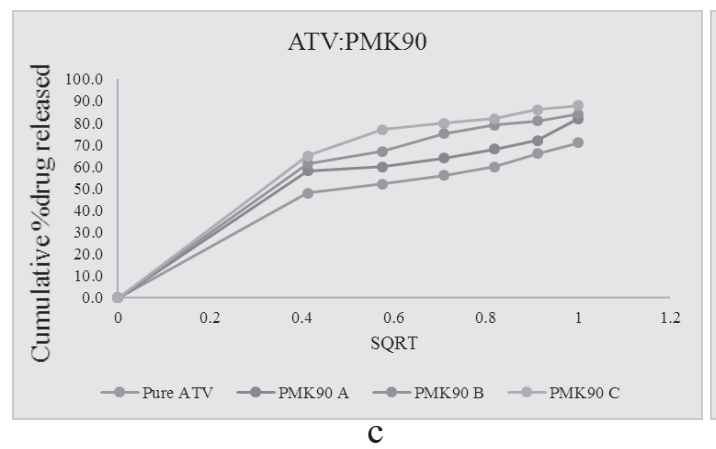

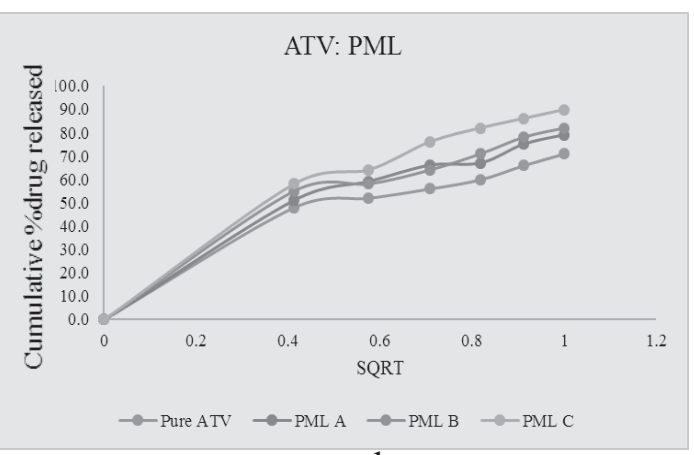

b

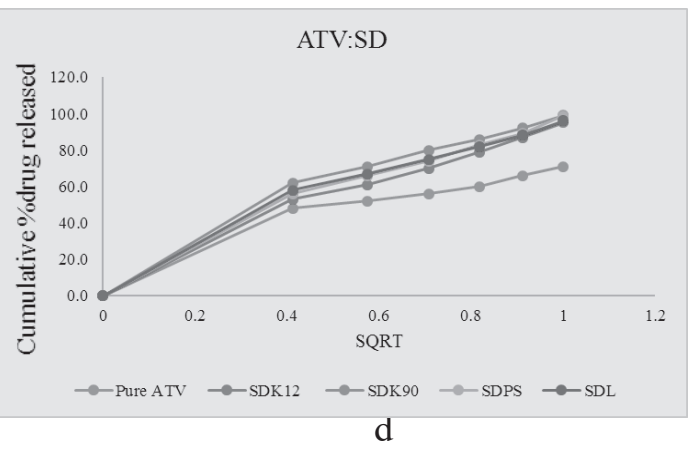

Fig. 9. Higuchi model release curves of ATV from physical mixtures (PMs) of ATV with Kollidon 12 (a), Lutrol

(b) and Kollidon 90 (c). Higuchi release curves of pure ATV and ATV solid dispersion formulations (d) with Kollidon 12, Lutrol and Kollidon 90. 
and polymers were: Higuchi model $>$ Hixson Crowell $>$ First order $>$ Zero order

The dissolution profile of ATV of two common marketed products (B1 and B2) was checked for 60 minutes (Fig. V and Fig. 8). The cumulative releases were $68.9 \%$ (B1) and $73.1 \%$ (B2) which are also found to be lowered than the solid dispersion formulations. Among the ternary SD formulations the highest ATV release rate was found for atorvastatin-kollidon $90 \mathrm{~F}$ formulations. When the release data of ATV from atorvastatin-kollidon $90 \mathrm{~F}$ formulation was compared to the marketed product, it was found much higher (Fig. 5).

Overall, the order of the carrier in enhancing the release of atorvastatin was found as atorvastatin calcium ternary $\mathrm{SD}>$ atorvastatin calcium binary SD $>$ pure atorvastatin calcium. In all cases, ternary solid dispersion showed a better cumulative percentage of dissolution than the physical mixture. The order of the carriers in enhancing the release of atorvastatin was found as kollidon $90 \mathrm{~F}>$ pregelatinized starch $>$ kollidon $12 \mathrm{~F}>$ pure atorvastatin. Dong et al, (2018) enhanced the dissolution rate of atorvastatin by hydrophilic carrier poloxamer 188. Croscarmellose sodium, microcrystalline cellulose and lactose were used to prepare solid dispersion (SD) formulations of atorvastatin by Asif Iqbal et al, (2020). Bobe et al, (2011) previously increased the dissolution rate of atorvastatin from $55 \%$ to $85 \%$ using mannitol, PVP-K30 and PEG 4000. Solid dispersion (SD) formulations of atorvastatin prepared by polyethylene glycol 4000 increased the release rate up to $91.66 \%$ (Shamsuddin et al., 2016). The polymers used in the current study (kollidon $90 \mathrm{~F}, 12 \mathrm{~F}$, lutrol and pregelatinized starch) showed excellent dissolution profile and, in some instances, performances were higher than the other polymers reported previously (Bobe et al., 2011).

\section{Characterization of the best formulation}

FT-IR is a drug characterizing technique that helps to find out the drug-excipient interactions as well as the stability of the drug in a solid dispersion formulation (Miyazaki et al., 2011). The scanning resolution of FT-IR was performed at 1 $\mathrm{cm}^{-1}$ over the region of 4000-500 $\mathrm{cm}^{-1}$ (Sikdar et al., 2019). After analyzing, there were no significant shifts in the FT-IR peaks. However, there were some slight shifts of the peaks in binary and ternary solid dispersions which indicates the formation of solid dispersions with the respective carriers (Fig. 6).

The SEM photomicrographs showed that the long plate surface of pure atorvastatin calcium converted into the rough surface after fusion by the carriers (Fig. 7). Therefore, the crystalline atorvastatin turned/converted into an amorphous form (sarkar et al., 2014). This indicates the significant enhancement of water solubility as well as it was hypothesised that the bioavailability of atorvastatin calcium would also be improved.

\section{Conclusion}

In this study, poorly soluble and low bioavailable atorvastatin calcium was made highly water soluble using different polymers in a certain ratio $(1: 0.5,1: 1$ and $1: 2)$ by using physical mixing and SD techniques $(1: 2)$. After the dissolution profile study, it was found that ternary SD formulations gave higher drug release after one hour compared to the physical mixers, the pure drug and the marketed product. The order of the carriers enhancing the Atorvastatin calcium found was like kollidon $90 \mathrm{~F}>$ pregelatinized $\mathrm{starch}>$ lutrol $>$ Kollidon $12 \mathrm{~F}>$ pure atorvastatin. Moreover, there were no significant shifts in the FT-IR peaks and the SEM images showed that the longer plate-like form of atorvastatin calcium is converted into the rough surface when the SD was formulated by fusion with the carriers. That means the crystalline atorvastatin calcium was converted into amorphous form after the ternary SD formulation. So, it can be concluded that the solubility of atorvastatin calcium was increased in its ternary SD formulations. However, to describe the more precise characterization of the SDs of atorvastatin calcium (ATV), DSC (Differential Scanning Calorimetry) and XRD (X-ray Diffraction) analysis is necessary to perform.

\section{References}

Ahjel S and Dumitru L (2009), Enhancement of solubility and dissolution rate of different forms of atorvastatin calcium in direct compression tablet formulas, Farmacia. 57(3): 290-300.

Ali S and Eman Al-Khedairy E (2019), Solubility and Dissolution Enhancement of Atorvastatin Calcium using Solid Dispersion Adsorbate Technique, Iraqi J. Pharm. Sci. 28(2): 105-114. DOI: $10.31351 /$ vol28iss2.

Arunkumar N, Deecaraman M, Rani C, Mohanraj KP and Kumar KV (2009), Preparation and solid state characterization of atorvastatin nanosuspensions for enhanced solubility and dissolution, Int J Pharm Tech Res. 1(4): 1725-1730. 
Bobe K, Subrahmanya C, Suresh S, Gaikwad D, Patil M, Khade T, Gavitre B, Kulkarni V and Gaikwad U (2011), Formulation and evaluation of solid dispersion of atorvastatin with various carriers, Pharmacie Globale. 2(1):1-6.

Cavallari C, Fini A and Ceschel G (2013), Design of olanzapine/lutrol solid dispersions of improved stability and performances, Pharmaceutics. 5(4): 570-590. DOI: .org/ 10.3390 /pharmaceutics 5040570.

Charman WN (2000), Lipids, lipophilic drugs, and oral drug delivery-some emerging concepts, J. Pharm. Sci. 89(8): 967-978. https://doi.org/ 10.1002/ 1520-6017 (200008) 89:8<967:: AID- JPS1>3.0.CO;2-R.

Chaudhary A, Nagaich U, Gulati N, Sharma V, Khosa R (2012), Enhancement of solubilization and bioavailability of poorly soluble drugs by physical and chemical modifications: A recent review, J Adv Pharm Educ Res. 2(1):32-67.

Chiou L and Riegelman S (1971), Pharmaceutical applications of solid dispersion systems, J. Pharm. Sci. 60(9): 1281-1302.

Choi S and Park S (2017), Design of PVP/VA S-630 based tadalafil solid dispersion to enhance the dissolution rate, Eur J Pharm Sci. 97: 269-276. https://doi. org/10.1016/ j.ejps.2016.11.030.

Chowdary R and Rao S (2000), Investigation of dissolution enhancement of itraconazole by solid dispersion in superdisintegrants, Drug Dev. Ind. Pharm. 26(11): 1207-1211. https://doi.org/10.1081/DDC- 100100993.

Dong W, Su X, Xu M, Hu M, Sun Y and Zhang P (2018), Preparation, characterization, and in vitro/vivo evaluation of polymer-assisting formulation of atorvastatin calcium based on solid dispersion technique, Asian J. Pharm. Sci. 13(6): 546-554. https://doi.org/10.1016/ j.ajps.2018.08.010.

Friedrich H, Fussnegger B, Kolter K and Bodmeier R (2006), Dissolution rate improvement of poorly water-soluble drugs obtained by adsorbing solutions of drugs in hydrophilic solvents onto high surface area carriers, Eur. J. Pharm. Biopharm. 62(2): 171-177. https://doi.org/10.1016/ j.ejpb.2005.08.013.

Frizon F, Eloya J, Donaduzzi C, Mitsui M and Marchetti J (2013), Dissolution rate enhancement of loratadine in polyvinylpyrrolidone K-30 solid dispersions by solvent methods, Powder Technol. 235: 532-539. https://doi.org/10.1016/ j.powtec.2012.10.019.

Ha ES, Baek I, Cho W, Hwang S and Kim M (2014), Preparation and evaluation of solid dispersion of atorvastatin calcium with Soluplus ${ }^{\circledR}$ by spray drying technique, Chem. Pharm. Bull. 62(6): 545-551. https://doi.org/ 10.1248/cpb.c14-00030.

Herbrink M, Groenland S, Huitema A, Schellens J, Beijnen J, Steeghs N and Nuijen B (2018), Solubility and bioavailability improvement of pazopanib hydrochloride, Int. J. Pharm. 544(1): 181-190. https://doi.org/10.1016/ j.ijpharm.2018.04.037.

$\mathrm{Hu}$ L, Gu D, Hu Q, Shi Y and Gao N (2014), Investigation of solid dispersion of atorvastatin calcium in polyethylene glycol 6000 and polyvinylpyrrolidone, Trop. J. Pharm. Res. 13(6): 835-842. DOI: 10.4314/tjpr.v13i6.2.

Iqbal A, Hossain M, Shamim M, Islam M, and Siddique M (2020), Formulation, in vitro evaluation and characterization of atorvastatin solid dispersion, Trop. J. Pharm. Res. 19(6): 1131-1138. DOI: 10.4314/tjpr.v19i6.2.

Jahan R, Islam M, Tanwir A and Chowdhury J (2013), In vitro dissolution study of atorvastatin binary solid dispersion, J. Adv. Pharm. Technol. 4(1): 18-24. DOI: $10.4103 / 2231-4040.107496$.

Kalepu S and Vijaykumar N (2015), Insoluble drug delivery strategies: review of recent advances and business prospects, Acta Pharmaceutica Sinica $B$. 5(5): 442-453. https://doi.org/ 10.1016/j.apsb. 2015.07.003.

Kayes K, Islam M, Hamidur R and Saqueeb N (2019), A comparative study on Naproxen Sodium tablets formulating with different super disintegrants, GSC biol. pharm. sci. 9(3):076-084. https://doi.org/ 10.30574/gscbps.2019. 9.3.0234.

Kim J, Kim M, Park H, Jin S, Lee S and Hwang S (2008), Physicochemical properties and oral bioavailability of amorphous atorvastatin hemi-calcium using spray-drying and SAS process, Int. J. Pharm. 359(1-2): 211-219. https://doi.org/ 10.1016/j .ijpharm. 2008.04. 006. 
Lai F, Pini E, Angioni G, Manca M, Perricci J, Sinico C and Fadda A (2011), Nanocrystals as tool to improve piroxicam dissolution rate in novel orally disintegrating tablets, Eur. J. Pharm. Biopharm. 79(3): 552-558. https://doi.org/ 10.1016/j.ejpb. 2011.07.005.

Lawrence X Yu (1999), An integrated model for determining causes of poor oral drug absorption, Pharm. Res. 16(12): 1883-1887. https://doi.org/ 10.1023/A: 1018911728161 .

Maurya D, Belgamwar V, and Tekade A (2010), Microwave induced solubility enhancement of poorly water soluble atorvastatin calcium, J. Pharm. Pharmacol. 62(11): 1599-1606. https://doi.org/ 10.1111/j.2042-7 158.2010.01187.x.

Merisko-Liversidge EM and Liversidge GG (2008), Drug nanoparticles: formulating poorly water-soluble compounds, Toxicol. Pathol. 36(1): 43-48. https://doi.org/10.1177/0192623307310946

Miyazaki T, Aso Y, Yoshioka S and Kawanishi T (2011), Differences in crystallization rate of nitrendipine enantiomers in amorphous solid dispersions with HPMC and HPMCP, Int. J. Pharm. 407(1-2): 111-118. https://doi.org/ 10.1016/ j.ijpharm. 2011.01 .035

Mukhtar RYA, Reid J and Reckless JPD (2005), Pitavastatin, Int. J. Clin. Pract. 59(2): 239-252. https://doi.org/ 10.1111/j.1742-1241. 2005.00461.x

Naqvi A, Ahmad M, Minhas MU, Khan KU, Batool F and Rizwan A (2020), Preparation and evaluation of pharmaceutical co-crystals for solubility enhancement of atorvastatin calcium, Polym. Bull. 77: 6191-6211. https://doi.org/10. 1007/s00289- 019-02997-4

Narasaiah L, Reddy K, Kishore K and Raj Ku (2010), Enhanced dissolution rate of atorvastatin calcium using solid dispersion with PEG 6000 by dropping method, J. Pharm. Sci. \& Res. 2(8): 484-491.

Pabari R, Jamil A, Kelly J, Ramtoola Z (2014), Fast disintegrating crystalline solid dispersions of simvastatin for incorporation into orodispersible tablets, Int. J. Pharm. Investig. 4(2): 51-59. DOI: 10.4103/2230-973X.133029.

Palem CR, Patel S and Pokharkar VB (2009), Solubility and stability enhancement of atorvastatin by cyclodextrin complexation, PDA J Pharm Sci Technol. 63(3): 217-225.
Patel M, Pandya N and Bhaskar VH (2011), Preparation, characterization and in vitro evaluation of repaglinide binary solid dispersions with hydrophilic polymers, Int J Drug Dev \& Res. 3(2): 111-121.

Rodde M, Divase G, Devkar T and Tekade A (2014), Solubility and bioavailability enhancement of poorly aqueous soluble atorvastatin: in vitro, ex vivo, and in vivo studies, BioMed Res. Int. 2014: 463895. https://doi. org/10.1155/ 2014/463895.

Sarkar R, AL-Hossain M, Islam S, Faroque ABM (2012), Effect of Hydrophilic Swellable Polymers on Dissolution Rate of Atorvastatin Using Simple Physical Mixing Technique, Ind. J. Novel Drug. Del. 4(2): 130-138.

Sarkar M, Hossain A, Sultana R and Faroque A (2014), Improvement solubility of atorvastatin calcium using solid dispersion technique, Int. J. Pharm. Sci. 5(12): 5405-5410.

Sarkar M, Sikdar K, Hossain A and Sharmin N (2021), Improving the drug dissolution profile of poorly aqueous soluble lovastatin using hydrophilic polymers by solid dispersion and physical mixing techniques, Natl J Physiol Pharm Pharmacol. 11(2): 216-221. DOI: 10.5455/njppp. 2021.11.123 47202022122020 .

Shamsuddin, Fazil M, Ansari H and Ali J (2016), Atorvastatin solid dispersion for bioavailability enhancement, J. Adv. Pharm. Technol. 7(1): 22-26. DOI: $10.4103 / 2231-4040.169873$.

Sharma D, Soni M, Kumar S, Gupta G (2009), Solubility enhancement-eminent role in poorly soluble drugs, Res J Pharm Technol. 2(2): 220-224.

Sikdar K, Ahamed A, Alam M, Sarkar M and Sajeeb B (2019), Formulation and in-vitro evaluation of bilayer tablets of atenolol and amlodipine, Bangladesh Pharmaceutical Journal. 22(2): 153-169.

Tantishaiyakul V, Kaewnopparat $\mathrm{N}$ and Ingkatawornwong S (1999), Properties of solid dispersions of piroxicam in polyvinylpyrrolidone, Int J Pharm. 181(2): 143-151. https://doi. org/10.1016/S0378 $-5173(99) 00070-8$. 